\title{
Analysis of the game characteristics of the female U14 juniors final matches at World Junior Tennis Finals in 2017
}

\author{
Ondřej Janák, Jiří Zháněl
}

Faculty of Sport Studies, Masaryk University Brno

\begin{abstract}
Analysis of the course of a match serves in many sports as a tool to obtain feedback for players and coaches. The most common method of analysis in tennis is the analysis of game characteristics which is used in the training process both in pre-match preparation and post-match analysis. The results of this analysis, centre on different ages and performance cohorts, are published in a number of studies. At present, special computer software is often used to analyze game characteristics in tennis - IBM Slam Tracker is used on all four grandslam tournaments. Game characteristics processed with this software have been taken into account when choosing 13 game characteristics used in our research. The aim of the research was to analyze the game characteristics of the best female junior players $(n=4)$, participants of the World Junior Tennis Finals (WJTF) final in 2017 in Prostejov. Based on the analysis of the research data, the differences in the level of the game characteristics of the winning and defeated finalists were determined, then comparison of the game characteristics of finalists WJTF 2017 and finalists of the women tournament at Roland Garros (RG) 2017 was carried out. In the final matches between Ukraine (UA) and the United States (US), the selected game characteristics were evaluated using the Dartfish 9.0 software. The results of the analysis of the game characteristics showed that the winning players gained more points after the first and second serve in both matches. The winning players also obtained more breaks and winners, committing a significantly lower number of double faults and unforced errors. When comparing the level of game characteristics of the winning players at WJTF, it was found that they had a higher success rate of the first serve than the RG winner and had a higher success rate in the number of gained breaks. It was found that the $R G$ winner had a significantly higher ratio of winners over a defeated player than it was by winners at WJTF. The ratio of total points won by the winning players versus the losers was higher for the WJTF than for the RG winner, which suggests a more balanced match at the RG final.
\end{abstract}

Key words: female junior players, comparison, software Dartfish, tennis, feedback

\section{Introduction}

Analysis of game characteristics - in addition to the most commonly used game characteristics, the terms of match characteristics, match-play features, tennis metrics, match statistics, performance indicators (Albamonte, 2011; Bedford, Barnett, Pollard \& Pollard, 2010; Brody, 2004; Cross \& Pollard, 2009; Filipcic, Filipcic \& Berendijas, 2008; Choe, O’Donoghue \& Hughes, 2009; Tudor, Zecic \& Matkovic, 2014) - is a significant feedback to both coaches and players in a range of collective and individual ball sports (Hohmann, Lames \& Letzelter, 2007). These analysis are common in basketball, football, hockey, tennis, rugby, golf, etc. In tennis, analysis of the game characteristics has become a common part of the training process, especially during pre-match preparation when choosing the optimal strategy and tactics of the game with respect to the opponent. Post-match analysis is used mainly to assess the reasons for a victory or loss in a match and to use this knowledge in training. The analysis of game characteristics allows to formulate the goals of the training, to evaluate strategy and tactics, psychological readiness and to analyze 
the game of the opponent (Crespo \& Miley, 2003; Filipcic, Caks \& Filipcic, 2011; Filipcic et al., 2008; Schönborn, 2012). Sanz and Terroba (2012) emphasize that the most important element in the analysis process is not the information we have at our disposal but its correct interpretation and subsequent transfer to coaching practice. Instead of the previously used hand methods (Schönborn, 2012), Internet or software products such as SIMI Scout, Dartfish, Silicon Coach, Tennis Analytics, TennisStats (Hui, Lijuan \& Jinju, 2010; Terroba, Kosters, Varona \& Manresa-Yee, 2013) are used for tennis game analysis, which allow to track the analysis of game characteristics from the most important tournaments during and after the game on TV screens or on the Internet. For the analysis of game characteristics, all four grandslam tournaments use the IBM SlamTracker software to evaluate 12 game characteristics. Game statistics are available to players and coaches after the match, and they can be searched for on dedicated web sites (e.g. www.matchstat.com, www.atpworldtour.com or www.oncourt.info). Dartfish software can also be used to analyze game characteristics using predefined gaming indicators, the evaluation is based on the principle of marking selected game activities during the game from the video. A number of tennis experts have dealt with analysis of game characteristics in tennis matches in the long term. Brody (2004) analyzed men's servis and found out that for winning games after own serve is a decisive number of points won after own serve, not the high percentage of serves in. Choi et al. (2009) concluded that the winning players are mostly better only in some game characteristics, with the resulting characteristics not necessarily in line with the course of the match. Kachel et al. (2015) found that the pressure in tennis balls had an impact on the level of game characteristics in both male and female games and found that this factor mainly affected the exchange rate and the correct timing of bumper hit. In a comprehensive analysis of 72 grandslam tournaments in 1991-2009, Cross et al. (2009) found out that about one-third of all the played men's rallies are ended by the winners, one-third ends with unforced errors and one-third ends with forced errors. The importance of different game characteristics in men's matches on different surfaces was presented by Katic, Milat, Zagorac \& Durovic (2011). They found that during the Wimbledon (W) tournament (grass courts), the key game characteristics concerned the serve while the Roland Garros (RG) tournament results mainly on the characteristics of the forehand and the backhand from the baseline. An interesting demonstration of the use of the results of the game characteristics analysis when assessing the game strategy was presented by Tudor et al. (2014), who surveyed the differences in game characteristics of men's matches between 2010 and 2011 in three grandslam tournaments RG, W and US Open (USO). The authors found that statistically significant differences in game characteristics between the two years were the least manifested in the RG, but there was a significant increase in the number of unnecessary errors - as opposed to the W and USO tournaments, when there was a decrease. In all three tournaments, there was a significant slowdown in first and second serve in 2011, and W and USO tournaments saw a decrease in the number of winners. These facts are attributed to a change in the style of the game where the prevailing tendency to a safer, less risky game prevails on fast surfaces (W and USO), while on slow courts (RG) there is a clear tendency for an aggressive game. Some authors (Terroba et al., 2013) dealt with the analysis of tennis players - men and women - on the court and using special algorithms in video analysis they found that the place where tennis players predominantly play balls is closely related to their gaming tactics.

On the basis of the synthesis of knowledge and previous studies, the research objective was formulated by finding the differences in the level of the game characteristics of the top female juniors - World Junior Tennis Finals (WJTF) finalists in 2017 in Prostejov (Czech Republic). Subsequent comparison of the game characteristics of finalists WJTF 2017 and finalists of the women tournament at Roland Garros (RG) 2017 was supposed to find out differences between two categories - juniors and adults. The text is conceptually based on previously published works 
by Janak, Paces \& Zhanel (2017) and Polach, Zhanel, Paces \& Cernosek (2016) dealing with the analysis of the game characteristics of junior players in 2013 and 2014.

\section{METHODS}

The basis for the game characteristics' analysis of the final matches (August 12, 2017) of the female junior teams $(n=4)$ of Ukraine (UA) and United States of America (US) at the WJTF 2017 (clay) were videorecordings of both final single matches. The research data were obtained from the videorecordings of each final single match by the observation method using the Dartfish 9.0 software. Individual game characteristics were selected based on the analysis of foreign studies, publications and statistical software, especially considering game characteristics which are used in IBM SlamTracker. Based on consultations with tennis trainers and experts, the 13 most significant game characteristics were chosen:

number of aces

number of double faults

success rate of the first serve in (\%)

number of points won after the first serve

number of points won after the second serve

number of return points won

number of forehand winners

number of backhand winners

number of forehand unforced errors

number of backhand unforced errors

number of net points won

success rate of breakpoints won (\%)

number of total points won

The research data obtained from the final single matches were compiled into tables which enabled to compare the individual game characteristics of both the winner and the defeated player. The analysed game characteristics of the juniors (WJTF 2017) were then compared with the women's singles final's data at RG 2017 tournament. There were 3 sets played in RG final and higher absolute values on the number of serves, returns, winners, unforced errors and breakpoints of RG final players were reached. Simple comparison would not provide such a valid data. Given this fact, relative numbers, resp. ratios between single game characteristics were used and then these ratios between two monitored categories (juniors and adults) were compared.

We have formulated two research questions:

1. What are the differences in the level of game characteristics of winning and defeated players in WJTF 2017 final matches?

2. What are the differences in the level of game characteristics of the world's top female juniors and female adult players?

\section{RESULTS}

\section{Analysis of the first match}

Second players of both teams - LK from Ukraine a GP from United States of America - participated in the first final match and the player of Ukraine won $(6: 3,6: 3)$. The analysis of the game characteristics of each set and for the match are listed in Table 1. 
Tab. 1: Analysis of game characteristics (first match)

\begin{tabular}{|l|c|c|c|c|c|c|}
\hline Set / match & \multicolumn{2}{|c|}{ First set $(6: 3)$} & \multicolumn{2}{c|}{ Second set (6:3) } & \multicolumn{2}{c|}{ Match $(6: 3,6: 3)$} \\
\hline Game characteristics/Players & LK (UA) & GP (US) & LK (UA) & GP (US) & LK (UA) & GP (US) \\
\hline Aces & 0 & 1 & 0 & 0 & 0 & 1 \\
\hline Double faults & 1 & 2 & 0 & 2 & 1 & 4 \\
\hline $\begin{array}{l}\text { First serve in } \\
\text { (\%) }\end{array}$ & $26 / 35$ & $19 / 26$ & $21 / 28$ & $16 / 22$ & $47 / 63$ & $35 / 48$ \\
\hline Points won after first srv. & $74 \%$ & $73 \%$ & $75 \%$ & $73 \%$ & $75 \%$ & $73 \%$ \\
\hline Points won after second srv. & 16 & 10 & 10 & 5 & 26 & 15 \\
\hline Return points won & 14 & 3 & 3 & 2 & 8 & 5 \\
\hline Winners - forehand & 7 & 6 & 17 & 13 & 31 & 28 \\
\hline Winners - backhand & 4 & 5 & 8 & 1 & 12 & 10 \\
\hline UE - forehand & 0 & 5 & 3 & 3 & 3 & 8 \\
\hline UE - backhand & 3 & 8 & 1 & 5 & 4 & 12 \\
\hline Net points won & 3 & 1 & 4 & 1 & 7 & 2 \\
\hline $\begin{array}{l}\text { Breakpoints won } \\
\text { (\%) }\end{array}$ & $2 / 3$ & $1 / 4$ & $4 / 4$ & $2 / 5$ & $6 / 7$ & $3 / 9$ \\
\hline Total points won & 34 & 28 & 31 & 20 & 65 & 48 \\
\hline
\end{tabular}

Notes: bold text ... winning player; $U E$... unforced errors

The match result and individual game characteristics indicate the unequivocal course of the match. Apart from the negligible difference in the number of aces (LK 0 vs GP 1), the winning player LK was better in almost all observed game characteristics. Only first serve in characteristic was comparable for as the defeated player (LK $75 \%$ vs GP $73 \%$ ), nevertheless the winning player LK won more points after her serve (LK 34 vs GP 20) and also return points won (LK 31 vs GP 28). The winning player also obtained more winners (LK 21 vs GB 16) and made less unforced errors (LK 7 vs GP 20). Bigger activity of the winning player LK is evidenced by the higher number of net points won (LK 7 vs GP 2). The player LK won 6 breakpoints out of 7 breakpoint opportunities. The number of total points won indicates that first set was tighter (LK 34 vs GP 28 ) than the second one (LK 31 vs GP 20) although the score was equal $(6: 3,6: 3)$. The winning player LK won 65 points in total against 48 total points won of the defeated player GP. The higher number of points won after the first serve, lower number of unforced errors and a higher number of breakpoints won are considered to be the most important game characteristics for the winning player LK.

\section{Analysis of the second match}

In the second match, player DL from Ukraine and player CG from the USA competed. The American player was more successful $(6: 4,6: 0)$. The analysis of the results is presented in Table 2 . 
Tab. 2: Analysis of observed game characteristics (second match)

\begin{tabular}{|l|c|c|c|c|c|c|}
\hline Set / match & \multicolumn{2}{|c|}{ First set $(4: 6)$} & \multicolumn{2}{c|}{ Second set (0:6) } & \multicolumn{2}{c|}{ Match $(4: 6,0: 6)$} \\
\hline Game characteristics/Players & DL (UA) & CG (US) & DL (UA) & CG (US) & DL (UA) & CG (US) \\
\hline Aces & 0 & 1 & 0 & 0 & 0 & 1 \\
\hline Double faults & 4 & 2 & 5 & 2 & 9 & 4 \\
\hline First serve in & $15 / 23$ & $18 / 27$ & $10 / 16$ & $16 / 17$ & $25 / 39$ & $34 / 44$ \\
$(\%)$ & $65 \%$ & $67 \%$ & $63 \%$ & $94 \%$ & $64 \%$ & $77 \%$ \\
\hline Points won after first srv. & 10 & 9 & 5 & 12 & 15 & 21 \\
\hline Points won after second srv. & 3 & 7 & 2 & 1 & 5 & 8 \\
\hline Return points won & 13 & 13 & 5 & 14 & 18 & 27 \\
\hline Winners - forehand & 2 & 9 & 2 & 2 & 4 & 11 \\
\hline Winners - backhand & 2 & 3 & 2 & 1 & 4 & 4 \\
\hline UE - forehand & 6 & 7 & 4 & 1 & 10 & 8 \\
\hline UE - backhand & 1 & 6 & 4 & 0 & 5 & 6 \\
\hline Net points won & 0 & 0 & 1 & 3 & 1 & 3 \\
\hline Breakpoints won & $2 / 3$ & $3 / 5$ & $0 / 1$ & $3 / 6$ & $2 / 4$ & $6 / 11$ \\
(\%) & $67 \%$ & $60 \%$ & $0 \%$ & $50 \%$ & $50 \%$ & $55 \%$ \\
\hline Total points won & 27 & 30 & 12 & 28 & 39 & 58 \\
\hline
\end{tabular}

Notes: bold text ... winning player; $U E$... unforced errors

Also, in this match, the result and individual game characteristics indicate the unequivocal course of the match. Different level of each game characteristic corresponds with unambiguous match result in favor of the tennis player CG, especially in the second set 6:0. The winning player CG reached first serve in of $94 \%$ which is unusually high value. In this set the winning player won 14 return points and made only 1 unforced error. The winning player was better in all game characteristics during the whole match. She scored 1 ace and made four double faults and the defeated player didn't score any aces and made 9 double faults (almost quarter of her serve). First serve in percentage (DL $64 \%$ vs CG $77 \%$ ) was increased by the winner in the second set. There is a big difference in total points won after own serve (DL 20 vs CG 29), return points won (DL 18 vs CG 27) and a number of winners. The American player scored triple the number of forehand winners in comparison to her opponent (DL 4 vs CG 11). The number of unforced errors (DL 15 vs CG 14) and net points won (DL 1 vs CG 3) are tighter. The winning player CG won 6 breakpoints and obtained 21 total points more than her opponent DL. The higher number of return points, winners and total points are considered to be the most important game characteristics for the winning player $\mathrm{CG}$.

\section{Comparison of the final matches of WJTF 2017}

Both final matches were comparable in both duration (76 min, resp. $59 \mathrm{~min}$ ) and a number of games played (18, resp. 16). The players of the first match (LK from Ukraine and GP from the USA) played more actively which is apparent from 21 winners scored by the winning player LK ( 9 forehands, 12 backhands) and 16 winners scored by the defeated player GP, total of 37 winners. In the second match, both players scored almost $1 / 3$ less winners ( 23 in total). In the first match, the players gained more net points (total of 9 points) whilst the players of second match obtained 4 net points altogether. The first serve in success rate was relatively high in both matches $(73 \%$, $75 \%$ and $77 \%$ ) apart from player DL (64\%). In the first match the players were more confident about the second serve, they made 5 double faults only whilst in the second match the players 
played a total of 13 double faults. It has been demonstrated by the game characteristics' comparison that winning players of both final matches scored more points after first serve (47:30 in total) as well as after second serve (16:10 in total). Also, the number of breakpoints won (total of 12:5) and winners (36:24 in total) was higher for the winning players. The winning players made less double faults (5:13) and unforced errors (total of 21:35).

Comparison of the game characteristics of first and second match with the $R G$ women's single final 2017 Participants of the RG 2017 women's final were SH from Romania (RO) and JO from Estonia (ES). JO won by 6:4, 4:6, 6:3. The analysis of this match's game characteristics is part of Table 3 .

Tab. 3: Comparison of the game characteristics of junior finals of WJTF 2017 and women's single final RG 2017

\begin{tabular}{|l|c|c|c|c|c|c|}
\hline Matches & \multicolumn{2}{|c|}{$\begin{array}{c}\text { WJTF First match } \\
(6: 3,6: 3)\end{array}$} & $\begin{array}{c}\text { WJTF Second match } \\
(4: 6,0: 6)\end{array}$ & \multicolumn{2}{c|}{$\begin{array}{c}\text { RG 2017 final } \\
(6: 4,4: 6,3: 6)\end{array}$} \\
\hline Game characteristics/Players & LK (UA) & GP (US) & DL (UA) & CG (US) & SH (RO) & JO (ES) \\
\hline Aces & 0 & 1 & 0 & 1 & 0 & 3 \\
\hline Double faults & 1 & 4 & 9 & 4 & 0 & 5 \\
\hline $\begin{array}{l}\text { First serve in } \\
(\%)\end{array}$ & $47 / 63$ & $35 / 48$ & $25 / 39$ & $34 / 44$ & $73 / 100$ & $55 / 96$ \\
\hline Points won after first srv. & $75 \%$ & $73 \%$ & $64 \%$ & $77 \%$ & $73 \%$ & $57 \%$ \\
\hline Points won after second srv. & 8 & 15 & 15 & 21 & 40 & 38 \\
\hline Return points won & 31 & 28 & 18 & 27 & 46 & 52 \\
\hline Winners (in total) & 21 & 16 & 8 & 15 & 8 & 54 \\
\hline UE (in total) & 7 & 20 & 15 & 14 & 10 & 54 \\
\hline Breakpoints won & $6 / 7$ & $3 / 9$ & $2 / 4$ & $6 / 11$ & $6 / 16$ & $8 / 19$ \\
(\%) & $86 \%$ & $33 \%$ & $50 \%$ & $55 \%$ & $38 \%$ & $42 \%$ \\
\hline Total points won & 65 & 48 & 39 & 58 & 94 & 102 \\
\hline
\end{tabular}

Notes: bold text ... winning player; UE ... unforced errors

Table 3 contains less game characteristics, since the statistics of the RG 2017 final match do not distinguish between forehand and backhand winners and forehand and backhand unforced errors neither net points won. Also, when comparing the WJTF matches with RG match, it is necessary to consider that there were 3 sets played at RG, therefore the number of total points won (196) is significantly higher than with WJTF matches (113 in the first match and 97 in the second match).

The WJTF winning player achieved a higher first serve success rate (75\%, resp. $77 \%$ ) in comparison to the winning player of RG (57\%). The similar level was found in the ratio of a number of points won after first and second serve by winning, resp. defeated players at WJTF (LK 3.3; CG 2.6; resp. GP 3.0; DL 3.0) whereas at RG this ratio was surprisingly lower for winning player JO (3.2) than for defeated player SH (5.0). In comparison to defeated players, the WJTF winning players scored more winners (LK 1.3; CG 1.9) however this ratio was significantly lower with the $\mathrm{RG}$ winner (JO 6.75). Fact that JO played more risky is also indicated by higher ratio value of the number of unforced errors compared to defeated player (JO 5.4), LK's and CG's ratios was lower again (2.9 and 0.9). In terms of the success rate of breakpoints won, the winning player of RG achieved $42 \%$ only whilst winning player of WJTF obtained significantly more, 86 \% (first match), resp. $55 \%$ of breakpoints (second match). The ratio of total points won was higher for the winning players of WJTF (1.35 first match; 1.49 second match) than the RG winning player (1.09) which suggest a tighter match at the RG finals. 


\section{DISCUSSION}

Most of the published studies of various authors are devoted mainly to the analysis of game characteristics in male tennis, respectively comparison of male and female tennis analysis. Analysis of game characteristics in female tennis was dealt with by Filipcic et al. (2011). Based on match analysis of 93 tennis players $(n=57)$ from the age of 12 to 23 , the authors searched in which game characteristics there are significant differences between the winning and the defeated players. They found that the winning players gained a significantly higher number of points both after their own serve and total points won (mean 30, resp. 64) against the defeated players (mean 16, resp. 31). In a previously unpublished study of the game characteristics level of the female junior final matches at WJTF 2013 between the CL from USA and SZ from Russia was found that in the first more equable match (CL vs. SZ - 2:6, 6:4, 6:3), the winner CL scored both more winners (CL - 37, SZ - 20) and more total points won (CL - 84, SZ - 80) than the defeated SZ. However, in the game characteristics of the success rate of the first serve (CL - 55\%, SZ - 61\%) and unforced errors (CL - 26, SZ - 19) the defeated Russian junior was better. In the second match (CB vs. EL - 6:1, 6:2) the american winning player CB was highly more successful than the defeated player EL from Russia in these analysed characteristics - number of winners (CB - 16, EL - 11), number of unforced errors (CB - 4, EL - 11), number of total points won(CB - 60, EL - 32). Nevertheless, this fact is obviously influenced by the clear result of the match. The above game characteristics were compared to the characteristics of the women's final match of the RG 2013 between SW from United States of America (US) and MS from Russia (RU) - SW vs. MS - 6:4, $6: 4$. Comparison of results showed that the winner of RG SW (US) played more aggressive tennis than winning players at WJTF 2013, she played a total of 10 aces of 35 first serves and 29 winners out of 71 total points won. The winner of the WJTF first final match CL (US) did not play any ace in her 20 first serves and played 37 winners out of 95 total points won. The second winner at WJTF EL (RU) played 2 aces of the 85 first serves and 16 winners out of 60 total points won. The defeated finalist at the RG MS (RU) was more successful only in the number of points won after the second serve and in the number of unforced errors. It can be stated that the game characteristics level of the defeated finalist at RG was comparable to the level of characteristics of the defeated juniors in the WJTF 2013 final matches.

In male tennis, the analysis of game characteristics at RG 2005 was pursued eg. by Filipcic et al. (2008), who found that the winning players played more aggressively - scored more aces (mean 1.43, resp. 1.33) and recorded more net approaches (mean 65.4, resp. 56.1), they also made less double faults (mean 0.9, resp. 1.3), unforced errors (mean 11.6, resp. 15.1), and achieved a higher percentage success rate of the first serve (60.3\%, resp. $57.5 \%)$. Cross et al. (2009) analyzed the speed of serves, the number of aces and double faults at grandslam tournaments in 1991-2009 in a total of 127 men's matches. They found that the number of aces generally increased due to the increased speed of serves, while the number of double faults decreases. They also found that most aces are achieved at Wimbledon (grass courts) every year (mean 2884), and that the number of aces is gradually decreasing from the USO (mean 2490), through the AO (mean 2096), those are courts with the artificial surface, to the RG on clay (mean 1819). The order is obviously closely related to the speed of the court surface in the individual tournaments. The influence of compression (inflating - compression resistance) of tennis balls on the game characteristics of junior tennis players was examined by Kachel et al. (2015). They found that this factor does not affect the number of winners, unforced errors, double faults, or success rate of the first serve. A total of 15 game characteristics for every 127 men's matches at the RG, W and USO tournaments in 2010 and 2011 were reviewed by Tudor et al. (2014). They came to the conclusion that the number of unforced errors increased on the slowest clay surface (mean 29.4, resp. 36.0) and decreased on the grass (mean 25.6, 22.8) and on concrete (mean 36.1, resp. 24.8). This phenomenon indi- 
cates an aggressive style of play on clay and more cautious on hard surfaces compared to 2010 and 2011. Similar findings have also been found by Katic et al. (2011) who compared the game characteristics of winning and defeated tennis players at Wimbledon and Roland Garros 2009. Their study shows that winning tennis players at Wimbledon have been more successful in game characteristic relating to serves and net playing. At RG especially the players who played more aggressively from the baseline and gained more winners and fewer unforced errors. Polach et al. (2016) and Janak et al. (2017) analyzed the junior's final matches at WJTF in 2013 and 2014 using the Dartfish software. The results of these authors' studies show that the decisive characteristics in the junior category are the number of winners and unforced errors, the more successful players commit a lower number of unforced errors (winning players - 88, defeated players - 103) and also get more winners (winning players - 44, defeated players - 38). It is more about a cautious style of play. The authors also found that compared with adult tennis players, juniors are more likely to gain breaks (juniors - 15/28, adults - 9/19), which suggests that junior's serve is not as important and dominant factor as in men's matches.

Comparing the published conclusions of the junior's analysis of the game characteristics, it is clear that in the age group U14 the differences between the game characteristics of male tennis players and female tennis players (winners and losers) are relatively small. The level of game characteristics of male juniors and female juniors is closely related to tactical concepts in individual matches and greater differences are evident mainly in the adult category.

\section{CONCLUSIONS}

Comparing the level of game characteristics of the winning and defeated players in both WJTF 2017 final matches showed that the winning players gained more points after first serve, second serve and in total than losers in both matches. In the first match winning player obtained more breaks and winners, while committing a significantly less unforced errors. She also played significantly more winning points at the net, because she played more variably. In the second match the number of winners was the most significant difference - winning player gained almost twice as much as the defeated player. Generally, the level of the winning players' game characteristics was higer, while in both matches different characteristics were decisive. Comparison of top junior and top adult players' game characteristics showed that WJTF 2017 winning players achieved a higher success rate of the first serve than the RG 2017 winner and also had a significantly higher success rate in the number of gained breaks. The RG winner was found to have a significantly higher ratio of winners against the defeated player than the WJTF winners. The ratio of the total points won by winning players versus the losers was higher for the WJTF than for the RG winner, which also (as three sets played) suggests a tighter match in the RG 2017 final. Difference in the level of the game characteristics between junior and adult players was not found in this study.

\section{Acknowledgement}

This publication was written at Masaryk University as part of the project „Diagnosis of the level of sports-specific motor preconditions in the context of the influence of age, somatic, gender aspects and lateral asymmetries in sport" number MUNI/A/1087/2017 with the support of the Specific University Research Grant, as provided by the Ministry of Education, Youth and Sports of the Czech Republic in the year 2018. 


\section{References}

Albamonte, M. (2011). Tennis Metrics. ITF coaching and sport science review, 55, 19-20.

Bedford, A., Barnett, T., Pollard, Gr. \& Pollard, Ge. (2010). How the interpretation of match statistics affects player performance. Journal of medicine and science in tennis, 15(2), 25-29.

Brody, H. (2004). Match statistics and their importance. ITF coaching \& sport science review, 32, 11-12.

Crespo, M., \& Miley, D. (2003). ITF advanced coaches manual. London: ITF Ltd.

Cross, R. \& Pollard, G. (2009). Grand Slam men's singles tennis 1991-2009 serve speeds and other related data. ITF coaching \& sport science review, 49, 8-10.

Filipcic, A., Caks, K. K., \& Filipcic, T. (2011). A comparison of selected match characteristics of female tennis players. Kinesiologia Slovenica, 17(2), 14-24.

Filipcic, T., Filipcic, A. \& Berendijas, T. (2008). Comparison of game characteristics of male and female tennis players at Roland Garros 2005. Acta Universitatis Palackianae Olomucensis, Gymnica, 38(3), 21-28.

Hohmann, A., Lames, M., \& Letzelter, M. (2007). Einführung in die Trainingswissenschaft. Wiebelsheim: Limpert Verlag.

Hui, Z., Lijuan, Y., \& Jinju, H. (2010). Computer-aided game analysis of net sports in preparation of Chinese teams for Beijing olympics. International journal of computer science in sport, 9(3), 53-69.

Choi, H. J., O'Donoghue, P. G. \& Hughes, M. D. (2009). A comparison of whole match and individual set data in order to identify valid performance indicators for real-time feedback in men's single tennis matches. In Lees, A., Cabello, D. \& Torres, G. Fourth World Congress of Science and Racket Sports. Madrid: SBA, 227-231.

Janak, O., Paces., J. \& Zhanel, J. (2018). Analysis of the game characteristics of a final juniors match U14 at World Junior Tennis Finals - WJTF in 2014 (case study). In Zvonar, Martin; Sajdlova, Zuzana. 11 th International Conference On Kinanthropology "Sport and Quality of Life". Brno: Masarykova univerzita, 815-825.

Kachel, K., Buszard, T. \& Reid, M. (2015). The effect of ball compression on the match-play characteristics of elite junior tennis players. Journal of Sports Sciences, 33(3), 320-326. http://dx.doi.org/10.1080/02640414.2014.942683.

Katic, R., Milat, S., Zagorac, N. \& Durovic, N. (2011). Impact of Game Elements on Tennis Match Outcome in Wimbledon and Roland Garros 2009. Collegium Antropologicum, 35(2), 341-346.

Matchstat.com. Retrieved February 2, 2018 from https://matchstat.com/tennis/h2h-odds-bets/Simona\%2OHalpec/ Jelena\%20Ostapenko.

Polach, M., Zhanel, J., Paces, J. \& Cernosek, M. (2016) Analysis of the game characteristic of a final juniors mach up tp 14 years at world junior tennis finals. In Zvonar, Martin; Sajdlova, Zuzana. 10th International Conference On Kinanthropology "Sport and Quality of Life". Brno: Masarykova univerzita, 168-178.

Sanz, D. \& Terroba, A. (2012). New technologies applied to tactical analysis in tennis. ITF coaching \& sport science review, $56,22-23$.

Schönborn, R. (2012). Strategie und Taktik im Tennis: Gelnhausen: Wagner Verlag.

Terroba, A., Kosters, W.,Varona, J. \& Manresa-Yee, C. (2013). Finding optimal strategies in tennis from video sequences. International Journal of Pattern Recognition and Artificial Intelligence, 27(6), 1-31.

Tudor, P. B., Zecic, M. \& Matkovic, B. (2014). Differences between 2010 and 2011 performance indicators of tennis play at the grand slam tournaments. Kinesiology 2014 Supplement, 46, 101-106. 